\title{
Innovative Multilayer Polymer-glass Composites Reinforced with Metal-ceramic Foam
}

\author{
Katarzyna Gawdzińska ${ }^{1, a}$, Janusz Grabian ${ }^{1}$, Dorota Nagolska ${ }^{2}$ and Barbara Kwiecińska ${ }^{3}$ \\ ${ }^{1}$ Maritime University of Szczecin, Faculty of Marine Engineering, ul. Willowa 2-4, 71-650 Szczecin, Poland \\ ${ }^{2}$ Poznan University of Technology, Faculty of Mechanical Engineering and Management, ul. Piotrowo 3, \\ 60-965 Poznan, Poland \\ ${ }^{3}$ Maritime University of Szczecin, Faculty of Navigation, ul. Willowa 2-4, 71-650 Szczecin, Poland
}

\begin{abstract}
When selecting the materials used in transport, in addition to the set of strength properties, which form the basis of the structural calculations, the possibility of weight reduction and the limitation of fire risks and maintenance activities should also be taken into account. The article provides a short description of both metal and metal-ceramic foams, as well as studies on multilayer sandwich composite materials. They consist of polyester-glass laminates and composite-ceramic foams. These materials were subjected to a technological three-point bending test. Such materials can replace the polyester-glass laminates that are commonly used in maritime transport and other industries.
\end{abstract}

\section{Introduction}

Composite materials constitute the most promising and quickly developing group of modern construction materials [1-5], which, due to desirable usability properties, are very popular among representatives in the fields of science, technology, industry and business. The guiding principle that has lead to the construction of composites is the desire to obtain a material with specific, expected properties, which largely depend on the technology used. In order to obtain the desired result, two or more materials with different properties are usually combined. The bi-component or multi-component nature of the composite, allows the beneficial characteristics of the components to be used, while reducing the adverse ones. Composite polymeric materials are widely utilized, due to their low density and high mechanical strength, as well as their high resistance to many acids and bases. The use of composites of various materials, participation and type of consolidation phase is significantly reducing the mass of all types of structures and at the same time is reinforcing them [5-6]. A popular way of strengthening materials is to reinforce them with the use of sandwich materials in the form of mats and fabrics. Materials that have this type of reinforcement are called layered composites, laminates or sandwiches (in the latter, they combine ceramics, polymers and metals). Foams are another group of materials. The forecasts developed in the early 1990s, regarding the predictions of technologies and applications of new materials, indicated that more and more often in mechanical engineering, especially in equipment and transport systems, cellular materials produced from metals [7-8] will be used, which are commonly known as: "porous metals" "metal foams" or "metal sponges". The dynamics of the trends related to the anticipated introduction of these materials for machine

\footnotetext{
${ }^{a}$ Corresponding author : k.gawdzinska@am.szczecin.pl
} 
construction have been shown in Figure 1. These forecasts proved to be accurate and at the beginning of the second decade of the 21 st century the wider use of these materials is being observed, especially those made of light metals. Unlike monolithic materials, foams are characterized by the occurrence of designed discontinuities in the material that have a repetitive or varied shape, whose size and arrangement in the entire volume of the product is in an orderly or disordered manner, which results in significant differences in properties, changing the reactions of this material to external factors, e.g. temperature or load.

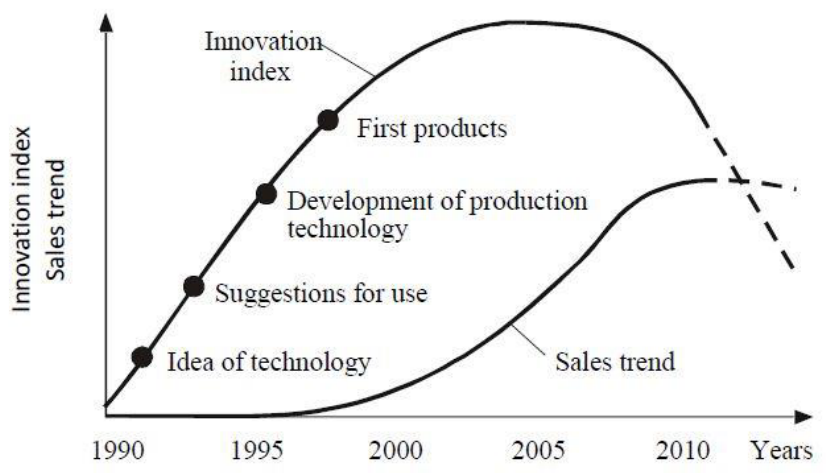

Figure 1. Forecast for the use of metal cellular materials in machine construction [1]

Metal foams (Fig. 2) can practically be made from all kinds of metals (except mercury). The most common foams are made of pure aluminium, as well as: magnesium, titanium, zinc, nickel, copper and iron or their alloys [6].

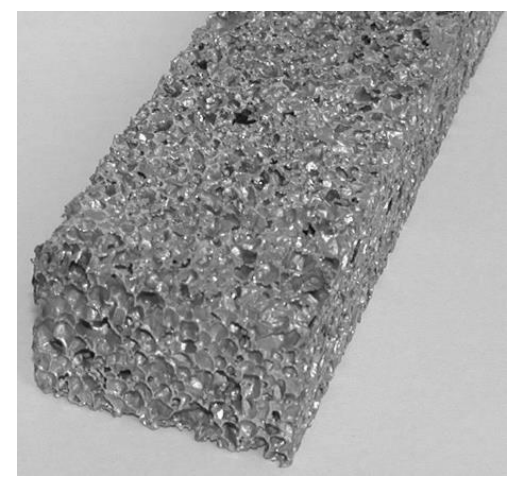

Figure 2. Metal foam (aluminium)

Metal foams have many unique properties that make them widely used in machine construction. Their low density means that they are an ideal filling material for layered structures that need high stiffness. Their low thermal conductivity makes it possible for them to be used as an insulating material, and the ability to damp vibrations suggests their use as damping liners. On the other hand, their tendency to deform considerably under the influence of loads can be used in systems that absorb impact energy or limit the effects of an explosion, as well as in the production of packaging. Cellular materials may exhibit both isotropy and anisotropy in their properties. According to the definition given in the literature $[1,3,6]$, metal foams are:

-porous materials, the construction of which can be described as a geometrically disordered arrangement of pores in a metal matrix,

-a metal material containing a considerable number of gas-filled pores in its volume. 
Metal foams with open pores (Fig. 3a) are used in heat exchangers, energy absorbing elements, as filters in the chemical industry, and catalyst components for internal combustion engines. They also have biological applications as silencers in flow installations, flame arresters, carriers of elements and as chemical compounds acting as catalysts for chemical processes, coming into contact with gaseous or liquid media, which are often chemically aggressive, and also have high temperatures. They are made of materials such as copper, nickel, iron, titanium, tantalum and their alloys [7-8].

a)

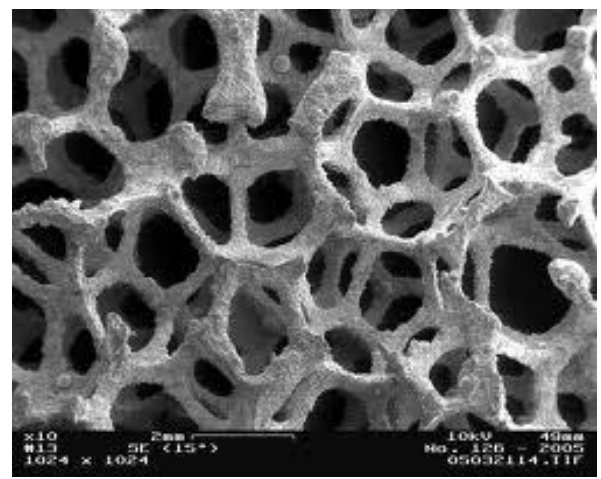

b)

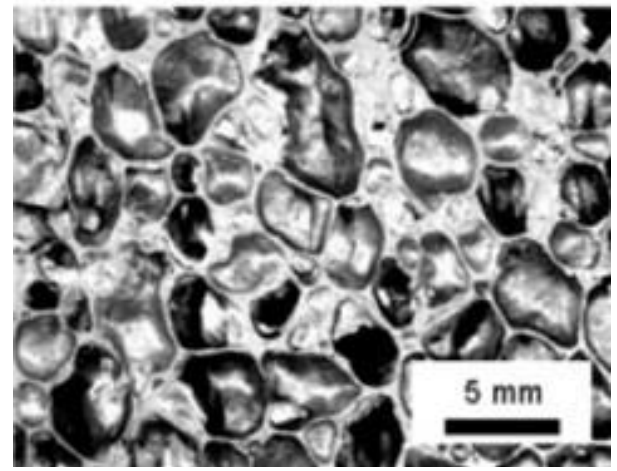

Figure 3. Example of foam structure: a) open pores [1], b) closed pores

Metal foams with closed pores (Fig. 3b) are used in mass-produced land transport, mainly in passenger cars, (in the body parts absorbing impact energy) increasing their stiffness as well as improving comfort of use by reducing vibrations and noise. This type of foam is also used in aircraft construction, general construction and elements of road infrastructure. Foams with closed pores are most often made of light metals, e.g. from pure aluminium, often with the addition of calcium.

The production of metal foams by the appropriate processing of pure metals or their alloys gives a certain, rather limited, area of change in the parameters which characterize these foams. The expansion of the functional range of the foams, as well as the possibilities of controlling them, can be provided by multiphase materials, these include composite materials. Metal-ceramic composites, with a wide range of composition, can be the starting material for the production of foams with special features specific to the shipbuilding area. Composite metal-ceramic foams, developed in accordance with the principles of material engineering, expand the possibilities of design. This paper has described multi-layer sandwich composite materials, in which the material of the spacer was composite metal-ceramic foam placed between polyester-glass composites in the form of a laminate. Plates made of this material were subjected to a three-point bending technological test.

\section{Research material}

The introduction of a spacer with special properties, between the two layers of the polymer-glass composite, is justified due to the way the material will work - under compressive stress as a result of local pressure and also resulting from the bending state, which may take place in the operating conditions of the vessel and in possible collisions. An innovative material that can be used in this case is aluminium foam with a specific gravity of $0.3-0.5 \mathrm{~g} / \mathrm{cm}^{3}$, which is made of aluminium foamed with a foam concentrate [8-9]. The foam can also be produced from an aluminium-ceramic composite by blowing gas into the liquid metal, and its internal structure can be controlled to some extent [9]. Such composite foams (AlSi11 matrix, SiC reinforcement, argon foaming gas) are manufactured at the Maritime University of Szczecin. Such foams have a specific resistance to compression, as shown in Figure 4. 

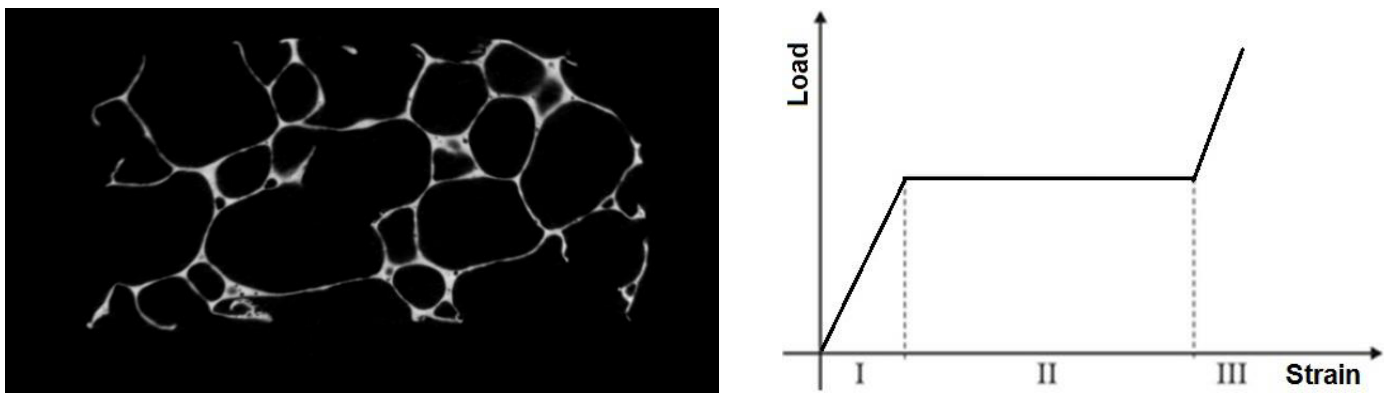

Figure 4. Aluminium-ceramic foam as a material for the spacer and its strength characteristics

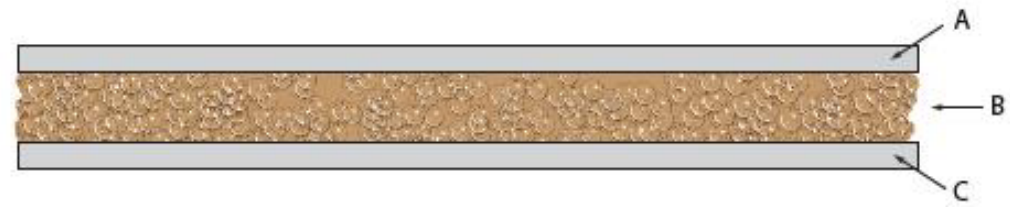

Figure 5. The proposed three-layer material for preliminary testing: A - polyester-glass composite, B aluminium foam, $\mathrm{C}$ - polyester-glass composite

The preliminary assessment of the suitability of the proposed material (Fig. 5) was based on a technological three-point bending test [9-12]. For research purposes related to the technological threepoint bending test, test panels with dimensions of $430 \times 200 \mathrm{~mm}$ were made as shown in Figure 6 . Polymer-glass composite laminates were made using Estromal 17 LM01 polyester resin together with METOX 50 hardener (in proportions of 1.5 percent by weight of hardener per unit volume) and twelve infiltrated layers of glass fiber fabric with a weight of $350 \mathrm{~g} / \mathrm{m}^{2}$. Multilayer composites were made using AlSi11/SiC foam layers $25 \mathrm{~mm}$ thick, laid and glued between two layers of polymer laminate. After 48 hours, $320 \times 60 \mathrm{~mm}$ samples were cut from the sample boards.

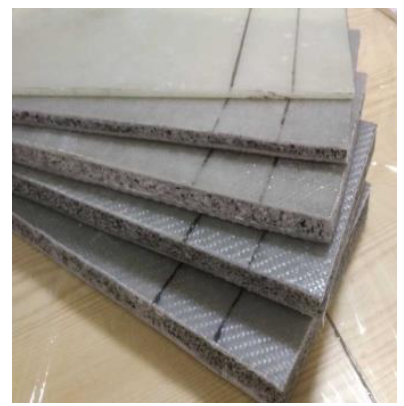

Figure 6. Test plates with dimensions of $430 \times 200 \mathrm{~mm}$

\section{Aims and test conditions}

The purpose of the preliminary tests was to determine the possible suitability of the multi-layer material presented above, as a replacement for the widely used polymer-glass composite. The satisfactory results of the technological three-point bending test, based on standard normalized bending tests of metals, polymers, plywood, etc., which determine sample dimensions and the geometry of the support system and load element, have been accepted as the basic criterion. To determine the behavior of the laminar material under load, resulting in deformation and its destruction, the load diagram shown in Figure 7 was adopted and carried out with the use of a testing machine using the tool from its equipment. 


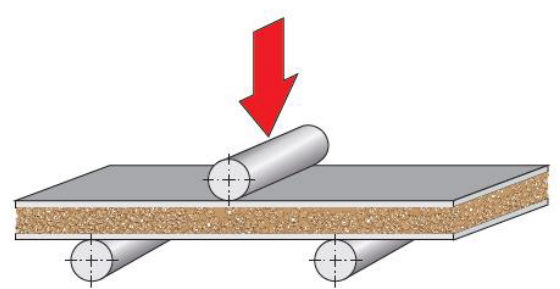

Figure 7. Scheme of the station for the adopted technological three-point bending test

A technological three-point bending test was carried out with the use of a testing machine and the appropriate instrumentation, examining the samples cut from test panels made of laminate-composite glass fiber - polyester resin as a reference level to the classical material, and new multilayer materials using fibreglass composite - polyester resin and aluminium-ceramic foams. The results of the technological test, carried out for samples with dimensions of $200 \times 60 \mathrm{~mm}$, which were laid on the support rollers which were at distance of $150 \mathrm{~mm}$ apart (for all samples), are shown in Figure 8.

Figure 9 shows the appearance of the samples after the bending test. It was possible to observe the various mechanisms of destruction of the multilayer materials, such as loosening of the outer layer, cracking in the axis of symmetry, as well as the foam spacer having been crushed in the area where the action of the deforming force had been applied.

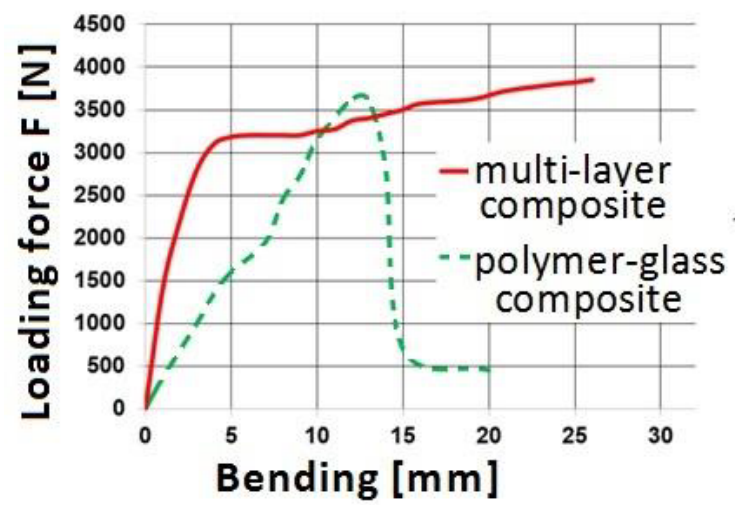

Figure 8. The combination of three-point bending curves of samples cut from different sample boards.

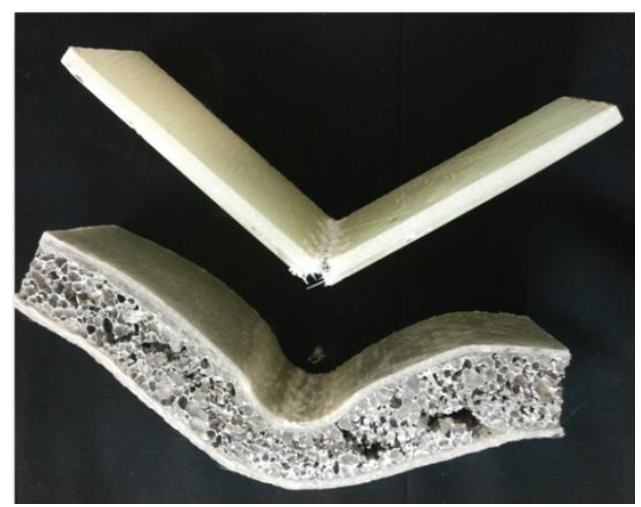

Figure 9. View of the destroyed samples

\section{Examples of the use of multilayer composites}

The properties of foamed metals, and especially the properties of the proposed multi-layer sandwich composite materials, make them a potential construction material for the transport industry, machine 
tool construction, the electrotechnical industry (applications in the construction of batteries, fuel cells and supercapacitors) as well as in the manufacture of chemical apparatus. Examples of the use of composite metal foams - metal in machine construction are shown in Figures 10-11.

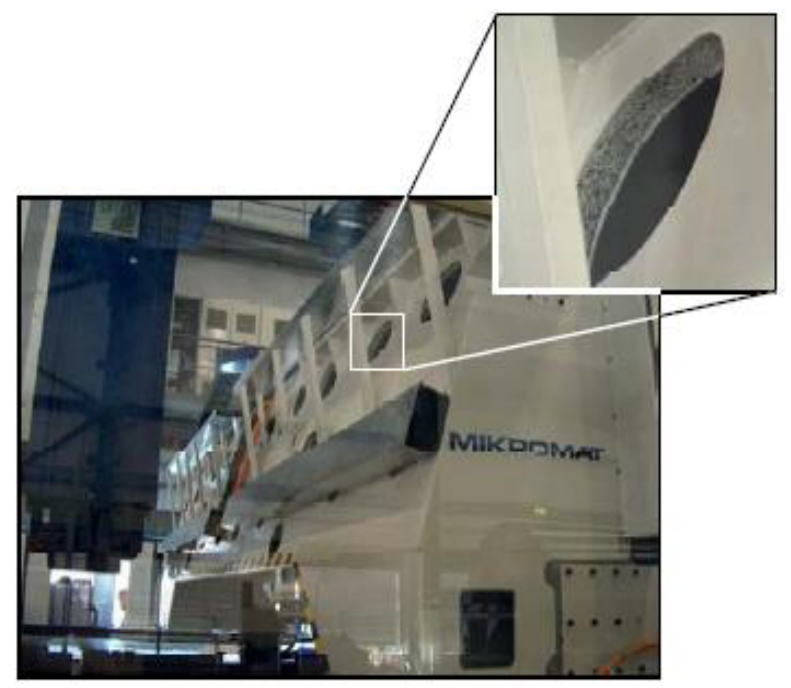

Figure 10. Acoustic cover of a large machine tool (milling machine) [13]
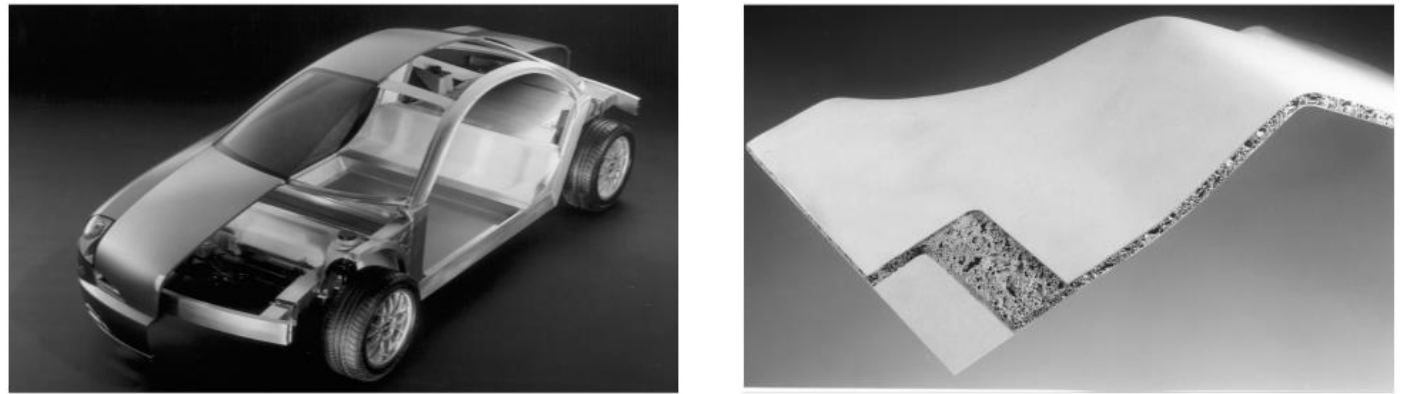

Figure 11. The use of aluminum foam in a car body structure [1]

\section{Conclusion}

Replacing widely used multi-layer composites with metal composites and polyester-glass composite will contribute to reducing the mass of the finished product. Adding a metal-ceramic foam spacer will increase the bending strength and thus also significantly increase their safety, e.g. in the case of ship collisions, due to its energy absorbing properties. This means that the materials in question can be widely used in the automotive and aerospace industries [14-15].

The mechanical, acoustic, chemical, fire resistant, thermal and electrical properties of composite metal foams and polyester-glass composites, as well as their considerable resistance to environmental conditions and the ever reducing costs of their production, make them competitive in some areas compared to the traditional materials used in various fields of mechanical engineering. They enable the use of complex construction solutions while reducing energy and fuel consumption, favourably affecting environmental protection, as well as improving the safety and comfort of the use of technical devices.

\section{Acknowledgments}


The research presented in this article was carried out under the Grant of the Ministry of Science and Higher Education of Poland $\mathrm{nr}$ 1/S/IESO/17: "Increasing operational effectiveness of complex technical systems by systematic development and implementation of innovations using novel materials and modifying the object's structure" performed at the Maritime University of Szczecin, Poland.

\section{References}

1. J. Grabian, Composite metal foam in the shipbuilding, (2012) (in Polish);

2. W. Ignalewski, Wpływ nowoczesnych technologii na rozwój statków śródlądowych w Europie, (2017);

3. K. Gawdzińska, L. Chybowski, A. Bejger, S. Krile, Determination of technological parameters of saturated composites based on sic by means of a model liquid, Metalurgija, Vol. 55 No. 4 November 2016, pp. 659-662, (2016);

4. F. Ashby, A. Evans, A. Flech, Metal Foams a Design Guide, (2000);

5. C. Fiebig, M. E. Steffen, S. Caba, M. Koch, Hybrid Composites of Plastic and Aluminium Foam, Euro Hybrid Materials and Structures 2016, p. 170-176, (2016);

6. K. Gawdzińska, L. Chybowski, W. Przetakiewicz, Proper matrix-reinforcement bonding in cast metal matrix composites as a factor of their good quality, Archives of Civil and Mechanical Engineering 16(3), p. 553-563, (2015);

7. G. Kaptay, Interfracial criteria for stabilization of liquid foams by solid particles. Colloids and Surfaces A: Physicochemical and Engineering Aspects Vol. 230 (1-3), 2004, 67-80;

8. PN-EN ISO 7438:2006 Metale - Próba zginania. Statyczna próba zginania techynologicznego;

9. K. Gawdzinska, K. Bryll, D. Nagolska, Influence of Heat Treatment on Abrasive Wear Resistance of Silumin Matrix Composite Castings, Arch. Metall. Mater., Vol. 61 (2016), No 1, p. 177-182, (2016);

10. J. Grabian, W. Ślączka, P. Pawłowska, W. Kostrzewa, The role of innovative composite materials in the safe and efficient operation of floating marine structures, Scientific Journals of the Maritime University of Szczecin, Vol. 52 (124), pp. 23-29, (2017);

11. R. Neugebauer, T. Hipke, J. Hohlfeld, R. Thümmler, Highly Damped Machine Tools with Metal Foam, International Conference "Advanced Metallic Materials", Smolenica, Slovakia, (5-7 November 2003);

12. D. Pulikowski, F. Lackner, C. Scheuerlein, D. Meinel, F. Savary, D. Tommasini, M. Pajor, Testing Mechanical Behavior of Nb3Sn Rutherford Cable During Coil Winding Vol. 27/4 (2017);

13. Aluminium foam, www.alueurope.eu/talat/lecture/1410.pdf.

14. M. Garcia-Avila, M. Portanova, A. Rabiei, Ballistic performance of composite metal foams. Composite Structures Vol. 125, 2015, 202-211;

15. T. Klepka, Construction of axial-symmetric polymeric extrudates of complex forms, Polimery Vol. 53/5. 2008, p. 390-395. 